\title{
Aortic valve replacement with a 17-mm mechanical prosthesis in octogenarian or older patients
}

\author{
Tatsuya Ogawa, PhD, MD, ${ }^{\text {a }}$ Masahiko Onoe, MD, ${ }^{\text {a }}$ Souji Moriwaki, MD, ${ }^{\text {a }}$ Keisuke Shioji, MD, ${ }^{b}$ \\ Ayumi Iwamuro, MD, ${ }^{\mathrm{b}}$ Takashi Uegaito, MD, ${ }^{\mathrm{b}}$ and Mitsuo Matsuda, $\mathrm{MD}^{\mathrm{b}}$
}

\section{ABSTRACT}

Objective: Few studies have reported on aortic valve replacement (AVR) in patients aged $>80$ years who have small aortic annuli. Various surgical techniques have been proposed for treating such patients. We investigated AVR using small-diameter mechanical valves, in patients aged $>80$ years, to determine its effectiveness.

Methods: Eighteen consecutive patients (15 women; 3 men) aged >80 (mean: $83.3 \pm 2.7$ ) years underwent surgical AVR with a $17-\mathrm{mm}$ prosthesis. The clinical status and results of pre- and post-operative echocardiography were evaluated. Midterm examination was conducted at $12.0 \pm 1.0$ months after AVR.

Results: The average preoperative body surface area of the patients was $1.39 \pm 0.15 \mathrm{~m}^{2}$; the average New York Heart Association functional class was $3.28 \pm 0.75$. Echocardiography showed a peak pressure gradient of $99.1 \pm 38.4 \mathrm{~mm} \mathrm{Hg}$. Operative mortality was absent. A significant decrease in the peak pressure gradient was found on early $(22.6 \pm 7.2 \mathrm{~mm} \mathrm{Hg})$ and midterm $(22.2 \pm 8.0 \mathrm{~mm} \mathrm{Hg})$ postoperative echocardiography, compared with that in the preoperative period. During this follow-up, 16 patients improved to class I, a significant change in each perioperative period compared with the preoperative period. No mortality was observed at 1 year postoperatively.

Conclusions: In patients aged $>80$ years who have small aortic annuli, AVR using a 17-mm prosthesis showed satisfactory clinical and hemodynamic results and provided a satisfactory remote prognosis. (J Thorac Cardiovasc Surg 2016;152:112-7)

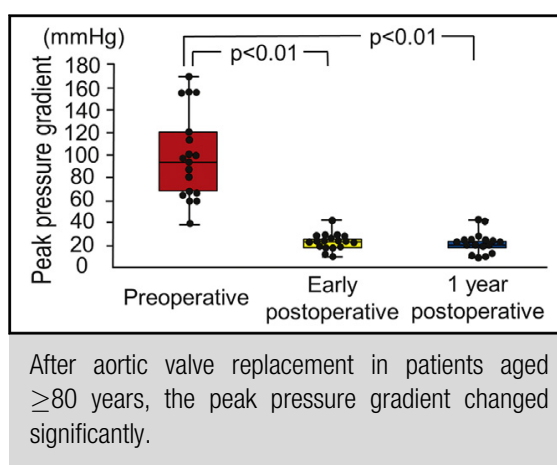

\section{Central Message}

Aortic valve replacement with a $17-\mathrm{mm}$ mechanical prosthesis is safe and effective in patients aged $\geq 80$ years who have small aortic annuli.

\section{Perspective}

Aortic bioprostheses of $<19 \mathrm{~mm}$ are commercially unavailable. More-invasive procedures for bioprosthesis implantation pose an unnecessary risk. We show that aortic valve replacement with a $17-\mathrm{mm}$ mechanical prosthesis is safe and effective in patients aged $>80$ years who have small aortic annuli. The NYHA functional class improved, to class I, in 16 patients. All patients survived to 1 year after operation.

See Editorial Commentary page 118.
After the first implantation of a St Jude Medical (St Paul, Minn) mechanical valve prosthesis, on October 3, 1977, this series of mechanical devices came to be widely accepted and has proven to be effective and durable. ${ }^{1}$ Their latest model, the SJM (for St Jude Medical) Regent, was modified to achieve a larger geometric orifice without changing the existing design of the pivot mechanism or blood-contact surface areas. Good outcomes have been reported. ${ }^{2}$ Anticoagulation should be carefully handled in

From the Departments of ${ }^{\mathrm{a}}$ Cardiovascular Surgery and ${ }^{\mathrm{b}}$ Cardiovascular Medicine, Kishiwada City Hospital, Kishiwada-shi, Osaka, Japan.

Received for publication Sept 30, 2015; revisions received Jan 14, 2016; accepted for publication Feb 8, 2016; available ahead of print March 23, 2016.

Address for reprints: Tatsuya Ogawa, PhD, MD, 610-136 Kanmatsu, Kishiwada, Osaka 596-0827, Japan (E-mail: tatsuyaogawa99@hotmail.com).

$0022-5223 / \$ 36.00$

Copyright (c) 2016 by The American Association for Thoracic Surgery

http://dx.doi.org/10.1016/j.jtcvs.2016.02.037 patients aged $>80$ years, because of potential complications. The actual effectiveness of small-diameter mechanical valves for patients aged $>80$ years is unknown. ${ }^{3-5}$

As far as we know, no commercially available bioprostheses are $<19 \mathrm{~mm}$. Although recent technical developments for aortic annulus enlargement (AAE) have been reported, ${ }^{6}$ the evolution of prosthetic valves themselves has made it possible to create larger effective orifice areas. For patients with aortic annuli $<19 \mathrm{~mm}$, we have attempted implantation of a 19-mm bioprosthesis, with AAE or aortic root replacement using a $19-\mathrm{mm}$ stentless valve. If

Scanning this QR code will take you to the article title page.

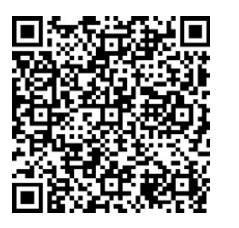




\section{Abbreviations and Acronyms \\ $\mathrm{AAE}=$ aortic annulus enlargement \\ AVR = aortic valve replacement \\ $\mathrm{LV}=$ left ventricular \\ NYHA $=$ New York Heart Association \\ PPM = patient-prosthesis mismatch \\ PT-INR $=$ prothrombin time-international normalized ratio \\ TAVR $=$ transcatheter AVR}

successful, these procedures could provide the benefit of hemodynamic improvement, while preventing patientprosthesis mismatch (PPM). However, such procedures carry the risk of prolonged crossclamp time and operation time and may be technically difficult in patients aged $>80$ years who have small aortic annuli.

We attempted to simplify the aortic valve replacement (AVR) procedure for patients who have small aortic annuli by suturing small-diameter mechanical valves. We investigated the early and midterm outcomes of AVR using a 17-mm SJM Regent prosthesis in patients aged $>80$ years who have small aortic annuli $(<19 \mathrm{~mm})$.

\section{METHODS}

\section{Study Population}

This study is a retrospective cohort study of 18 consecutive patients treated at this institution between March 2006 and April 2014. Patient data were obtained by review of clinical and surgical records. All patients were subjected to preoperative detailed heart assessments, including coronary angiography and transthoracic or transesophageal echocardiography, and they underwent surgery for aortic stenosis. In all patients, a 17-mm SJM Regent valve was implanted. Preoperative clinical features are summarized in Table 1.

\section{Echocardiography}

All patients in the study cohort underwent echocardiography at the laboratory center. Standard M-mode dimensions were collected according to the criteria of the American Society of Echocardiography. All Doppler measurements were obtained as the average of 3 cycles in patients with sinus rhythm, or as the average of more than 5 cycles in those who have atrial fibrillation. The peak and mean gradients across the prosthesis were calculated according to the modified Bernoulli equation. The left ventricular (LV) mass index was calculated from Reichek and Devereux's formula, ${ }^{7}$ and body surface area was calculated according to the Dubois formula. Echocardiography data were collected before the procedure, after the procedure (at patient discharge), and at a midterm follow-up (12.0 \pm 1.0 months after the procedure).

\section{Surgical Technique}

The operations were performed through a standard median sternotomy. Cardiopulmonary bypass was initiated after cannulation of the ascending aorta, superior vena cava, and inferior vena cava. A left ventricular vent was inserted by means of the right upper pulmonary vein. Mild hypothermia was applied. Cold-blood cardioplegia was applied intermittently, directly, and selectively to the coronary ostia. Prosthesis size was selected according to the size of the aortic annulus, which was determined using the manufacturer sizer. In all patients, prostheses were implanted at the intraannular position with simple interrupted sutures.

\section{Perioperative Anticoagulation Management}

Anticoagulation therapy with oral warfarin sodium was administered to all patients. The prothrombin time international normalized ratio (PT-INR) was measured at frequent intervals and monitored after patient discharge. In patients receiving mechanical aortic valves, anticoagulation therapy was administered with a target PT-INR of 1.8 to 2.5 . Acetylsalicylic acid $(100 \mathrm{mg} /$ day $)$ was administered to all patients as an antiplatelet agent.

\section{Follow-up}

Postoperative follow-up was performed at the clinic, and all follow-ups were completed. Events during the follow-up period were evaluated according to guidelines for reporting valve-related mortality and morbidity. ${ }^{8}$ The mean follow-up was $40.7 \pm 26.7$ months. All patients underwent transthoracic or esophageal echocardiography to evaluate LV ejection fraction, peak and mean gradients, and LV mass index at the following 3 time points: preoperatively, at the time of hospital discharge, and 1 year \pm 1.0 months after the operation.

\section{Statistical Analysis}

R software (version 3.2.3; The R Foundation; http://www.r-project.org) was used for statistical analysis. Continuous variables are reported as mean \pm standard deviation; categorical variables are reported as counts and percentages. The 2-way analysis of variance or the Steel Dwass multiple comparison test was used to compare data measured preoperatively with those at each point of follow-up. This investigation, including follow-up studies, was approved by the ethics committee and the institutional review board of Kishiwada (Japan) municipal hospital. Informed consent was obtained from all patients for the anonymous use of their data, including follow-up information.

\section{RESULTS}

\section{Early and Midterm Operative Outcomes}

The 30-day or in-hospital operative mortality was $0 \%$. Nine patients underwent associated procedures. Table 2 shows perioperative and postoperative data. As in-hospital complications, a cerebral infarction, a temporary hemodialysis, and a graft occlusion in concomitant coronary artery bypass grafting were observed in respective patients. No postoperative patients were in New York Heart Association functional class III or IV. Figure 1 shows the class data from before and after AVR. At the 1-year postoperative followup, no mortality or incidences of patient bleeding events, including gastrointestinal bleeding, pericardial effusion, and cerebral hemorrhage, were reported after their operations. As a morbidity, one patient had a mild paravalvular leak at the 1-year postoperative follow-up.

\section{Echocardiographic Follow-up}

At early and midterm follow-up, statistically significant decreases in peak pressure gradients were observed $(P<.01)$ between the preoperative period and each of the postoperative periods. In LV mass index, during follow-up, no statistically significant decrease was observed. Between the preoperative and midterm postoperative periods, $P=.184$. Statistically significant increases in LV ejection 
TABLE 1. Preoperative data

\begin{tabular}{|c|c|}
\hline Variable & Value \\
\hline Number of patients (women; men) & 15 (83.3); $3(16.7)$ \\
\hline Age (y) & $83.3 \pm 2.7$ \\
\hline Height $(\mathrm{cm})$ & $147.7 \pm 6.6$ \\
\hline Weight $(\mathrm{kg})$ & $48.0 \pm 9.8$ \\
\hline $\operatorname{BSA}\left(\mathrm{m}^{2}\right)$ & $1.39 \pm 0.15$ \\
\hline \multicolumn{2}{|l|}{ NYHA class } \\
\hline I & 0 \\
\hline II & $2(11.1)$ \\
\hline III & $8(44.4)$ \\
\hline IV & $8(44.4)$ \\
\hline Hypertension & $14(77.7)$ \\
\hline \multicolumn{2}{|l|}{ Diabetes } \\
\hline NIDDM & $2(11.1)$ \\
\hline IDDM & $1(5.6)$ \\
\hline Total & $3(16.7)$ \\
\hline Dyslipidemia & $5(27.8)$ \\
\hline Hyperuricemia & $4(22.2)$ \\
\hline ASO & $10(55.6)$ \\
\hline \multicolumn{2}{|l|}{ Smoker } \\
\hline Current & $2(11.1)$ \\
\hline Former & $1(5.6)$ \\
\hline Total & $3(16.7)$ \\
\hline \multicolumn{2}{|l|}{ Heart rhythm } \\
\hline Normal sinus & $11(91.1)$ \\
\hline Atrial fibrillation & $6(33.3)$ \\
\hline Pacing & $1(5.6)$ \\
\hline Creatinine & $1.20 \pm 0.59$ \\
\hline Creatinine clearance $(\mathrm{mL} / \mathrm{min})$ & $32.2 \pm 13.1$ \\
\hline EuroSCORE II & $10.23 \pm 6.44$ \\
\hline $\begin{array}{l}\text { Values are } \mathrm{n}(\%) \text {, with continuous data } \mathrm{p} \\
\text { less otherwise noted. } B S A \text {, Body surface } \\
\text { NIDDM, non-insulin dependent diabetes } \\
\text { mellitus; } A S O \text {, arteriosclerosis obliterans; } \\
\text { Operative Risk Evaluation. }\end{array}$ & $\begin{array}{l}\text { standard deviation, un- } \\
\text { ork Heart Association; } \\
\text { lin-dependent diabetes } \\
\text { ean System for Cardiac }\end{array}$ \\
\hline
\end{tabular}

fraction were not observed between the preoperative and either of the postoperative periods. Between the preoperative and midterm postoperative periods, $P=.069$. No structural failure of the prosthesis and no prosthetic endocarditis occurred. One patient had a mild paravalvular leak. Echocardiographic results are summarized in Table 3 and Figure 2.

\section{DISCUSSION}

The country of Japan is now facing unprecedented aging of the population. The prevalence of aortic stenosis associated with age-related degeneration has increased annually. Consequently, more patients aged $>80$ years become candidates for AVR. Contemporary outcomes of AVR in patients aged 80 years are excellent. ${ }^{9,10}$ The relatively small stature of Japanese patients aged $>80$ years poses a problem regarding AVR, as many have small aortic annuli.

Present options for small aortic valves $(<19 \mathrm{~mm})$ include use of a 19-mm bioprosthesis with AAE, root replacement using a $19-\mathrm{mm}$ stentless valve, transcatheter AVR (TAVR), and implantation of a 17-mm mechanical
TABLE 2. Perioperative and postoperative data

\begin{tabular}{|c|c|c|}
\hline Variable & Value & $\begin{array}{c}\text { Data by percentile } \\
(25 \text { th } / 50 \text { th } / 75 \text { th })\end{array}$ \\
\hline Hospital death (n) & 0 & \\
\hline Cardiopulmonary bypass time (min) & $179 \pm 30$ & $(202.3 / 177.5 / 159.3)$ \\
\hline Isolated operation & $162.4 \pm 22.1$ & $(172.3 / 159.5 / 150.5)$ \\
\hline Concomitant operation & $199.9 \pm 27.1$ & $(221.0 / 197.5 / 180.0)$ \\
\hline Crossclamp time (min) & $134 \pm 27$ & $(150.0 / 133.0 / 115.8)$ \\
\hline Isolated operation & $120.3 \pm 20.4$ & $(134.5 / 117.5 / 105.0)$ \\
\hline Concomitant operation & $151.1 \pm 25.6$ & $(163.0 / 145.5 / 134.0)$ \\
\hline Concomitant operation & $9(50.0)$ & \\
\hline Coronary artery bypass grafting & $6(33.3)$ & \\
\hline Tricuspid valve annuloplasty & $1(5.6)$ & \\
\hline $\begin{array}{l}\text { Mitral valve replacement }+ \text { ASD } \\
\text { closure }\end{array}$ & $1(5.6)$ & \\
\hline Axillary-axillary artery bypass & $1(5.6)$ & \\
\hline Intubation time $(\mathrm{h})$ & $25.6 \pm 19.5$ & $(36.4 / 18.7 / 13.8)$ \\
\hline Intensive care unit stay (d) & $2.7 \pm 2.1$ & $(3.8 / 2.0 / 1.0)$ \\
\hline Hospital stay (d) & $23.2 \pm 9.2$ & $(24.8 / 22.0 / 18.3)$ \\
\hline \multicolumn{3}{|l|}{ In-hospital complications } \\
\hline Coronary graft occlusion & $1(5.6)$ & \\
\hline Cerebral infarction & $1(5.6)$ & \\
\hline Reoperation for bleeding & 0 & \\
\hline Complete atrioventricular block & 0 & \\
\hline Temporary hemodialysis & $1(5.6)$ & \\
\hline \multicolumn{3}{|l|}{ Midterm morbidity* } \\
\hline Paravalvular leak & $1(5.6)$ & \\
\hline $\begin{array}{l}\text { Midterm death (1 y after } \\
\text { operation) }\end{array}$ & 0 & \\
\hline
\end{tabular}

prosthesis. AAE is reported to be comparable to AVR, with regard to early mortality, while the cardiopulmonary bypass time and crossclamp time are significantly prolonged in AAE compared with AVR. ${ }^{11,12}$ In patients who have small aortic annuli, Kulik and colleagues ${ }^{13}$ reported that AAE at the time of AVR is a safe procedure that decreases postoperative gradients and the incidence of PPM. However, AAE does not appreciably improve long-term clinical outcomes.

Some surgeons remain cautious. Dhareshwar and colleagues ${ }^{14}$ have pointed out that AAE itself does not increase operative risk, although it is most often required in high-risk patients. They advise that surgeons should not be reluctant to enlarge the aortic annulus to permit implantation of adequately sized valve prostheses. Peterson and colleagues ${ }^{6}$ concluded that AAE in the modern era is a safe adjunct to AVR and should be considered in selected patients to avoid PPM. They noted that young, active patients with relatively small aortic annuli are more likely to derive greater improvements in functional capacity, because implanting valves with effective orifice area indexes $<0.85 \mathrm{~cm}^{2} / \mathrm{m}^{2}$ has resulted in less symptomatic improvement after AVR. Accordingly, AAE probably is not required in patients 


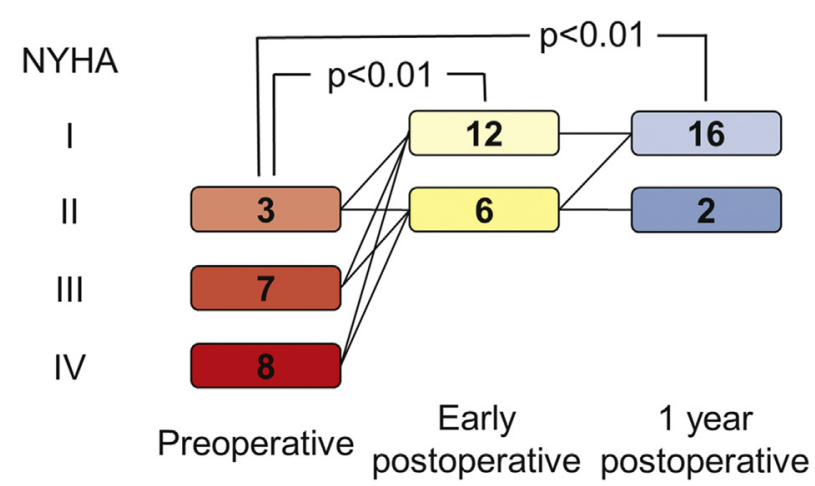

FIGURE 1. Statistically significant improvements were observed, in NYHA functional class data, between the preoperative values and each of the follow-up points. NYHA, New York Heart Association.

aged $>80$ years who are physically inactive, because the expected benefit would be small. Thus, we advise caution in recommending $\mathrm{AAE}$ to accommodate prostheses 1 to 2 sizes larger.

Aortic root replacement using a stentless valve is reported to be as safe as mechanical composite grafts in the perioperative period, and stentless valves are superior with regard to freedom from major adverse valve-related and cardiovascular events. ${ }^{15}$ With regard to bioprosthesis performance, a prospective randomized trial shows comparable outcomes with stentless versus stented bioprostheses, at 1 year after AVR. ${ }^{16}$ However, no level I or IIA evidence is available for stentless bioprostheses; Follow-up over the course of 15 years is necessary to compare the excellent results of stented bioprosthetic valves. ${ }^{17}$ Thus, root replacement using a stentless valve seems to have no advantage compared with surgical AVR with bioprosthesis, along with AAE.

Transcatheter AVR seems to be a more modern approach. A randomized trial comparing TAVR and surgical AVR in high-risk patients revealed similar 5-year mortality rates. ${ }^{18}$ Pibarot and colleagues ${ }^{19}$ reported that PPM is more frequent and more often severe after surgical AVR than after TAVR, and that TAVR may be preferable in patients who have small aortic annuli and are susceptible to PPM, to avoid its adverse impact on LV mass regression and survival. A lower incidence of severe PPM was observed in patients who have small aortic annuli $(<18 \mathrm{~mm})$ who had undergone TAVR. ${ }^{20}$

Consequently, TAVR seems to have reasonable potential for use in patients aged $>80$ years who have small aortic annuli. However, because this series estimated the mean EuroSCORE II (European System for Cardiac Operative Risk Evaluation) as $10.23 \pm 6.44$ as the level of risk, we hesitate to proceed straight to TAVR. Of these 18 patients, 8 had concomitant cardiac surgery. We see various surgical AVRs regarding concomitant procedures in a comparatively large cohort of patients aged $>80$ years, as follows: 269 of $1014(26.5 \%)^{21} ; 184$ of $345(53.8 \%)^{22}$; and 211 of 345 $(61.2 \%))^{23}$ The occurrence of concomitant procedures
TABLE 3. Echocardiographic data

\begin{tabular}{lccc} 
& & \multicolumn{2}{c}{ Postoperative } \\
\cline { 3 - 4 } \multicolumn{1}{c}{ Measure } & Preoperative & Early & Midterm \\
\hline Peak gradient $(\mathrm{mm} \mathrm{Hg})$ & $99.1 \pm 38.4$ & $22.6 \pm 7.2$ & $22.2 \pm 8.0$ \\
LVEDD $(\mathrm{mm})$ & $42.9 \pm 6.3$ & $39.6 \pm 8.9$ & $40.3 \pm 6.3$ \\
LVESD $(\mathrm{mm})$ & $26.9 \pm 9.0$ & $25.1 \pm 8.6$ & $23.7 \pm 5.8$ \\
LVMI $\left(\mathrm{g} / \mathrm{m}^{2}\right)$ & $126.7 \pm 45.3$ & $118.1 \pm 57.1$ & $95.6 \pm 35.7$ \\
Ejection fraction $(\%)$ & $66.5 \pm 18.3$ & $67.1 \pm 14.1$ & $72.4 \pm 12.3$ \\
\hline
\end{tabular}

Data are presented as mean \pm standard deviation. $L V E D D$, Left ventricular enddiastolic dimension; $L V E S D$, left ventricular end-systolic dimension; $L V M I$, left ventricular mass index.

cannot be neglected. We recognize the value of TAVR, but comparison of TAVR and isolated surgical AVR is difficult. Finally, the procedural choice of surgical AVR using a $17-\mathrm{mm}$ mechanical prosthesis is feasible for use in patients aged $>80$ years who have small aortic annuli.

As a major premise, the American Heart Association/ American College of Cardiology Guidelines ${ }^{24}$ indicate that a bioprosthesis for surgical AVR is reasonable in class-IIA patients aged $>70$ years. Despite those guidelines, in 2011, in the United States, $23.9 \%$ of patients aged $\geq 85$ years continued to receive mechanical prostheses. ${ }^{25}$ In our view, the choice of prosthesis for patients aged $>80$ years requires further discussion, as no significant evidence suggests that valve type affects overall survival, hospital morbidity, mortality, midterm survival, or late cardiac events. ${ }^{26,27}$ In a population confined to patients aged $>80$ years, significant superiority of mechanical prostheses emerged in survival rate ${ }^{28}$ and cardiac-related death rate. ${ }^{23}$ The choice of a mechanical prosthesis, because of the small size of the aortic annulus, could avoid complex additional procedures, such as AAE or root replacement. We should keep mechanical prostheses among our choices for decreasing surgical risks as much as possible.

The issue of anticoagulation is important in these particular patients. In this series, we controlled the PT-INR level to keep it between 1.8 and 2.5. This target level is comparatively lower than that recommended in the guidelines. ${ }^{24}$ In Asia, maintaining PT-INR at such lower levels is accepted in some institutions. ${ }^{5,29}$ Considering differences among races, Takaseya and colleagues ${ }^{4}$ reported that the target INR level should be higher in Caucasian than Asian patients because of differences between them in the pharmacodynamics of warfarin. Other reports recommend close monitoring of PT-INR. ${ }^{27,28}$

Appropriate and deliberate anticoagulation control is important, especially in this extremely elderly subset of patients. Ashikhmina and colleagues ${ }^{26}$ found that among elderly patients (aged $>70$ years) with bioprostheses, despite an initial attempt to avoid anticoagulants, $6 \%$ were prescribed long-term warfarin because of other health problems. Not all patients can avoid warfarin treatment, despite the choice of bioprosthesis. 

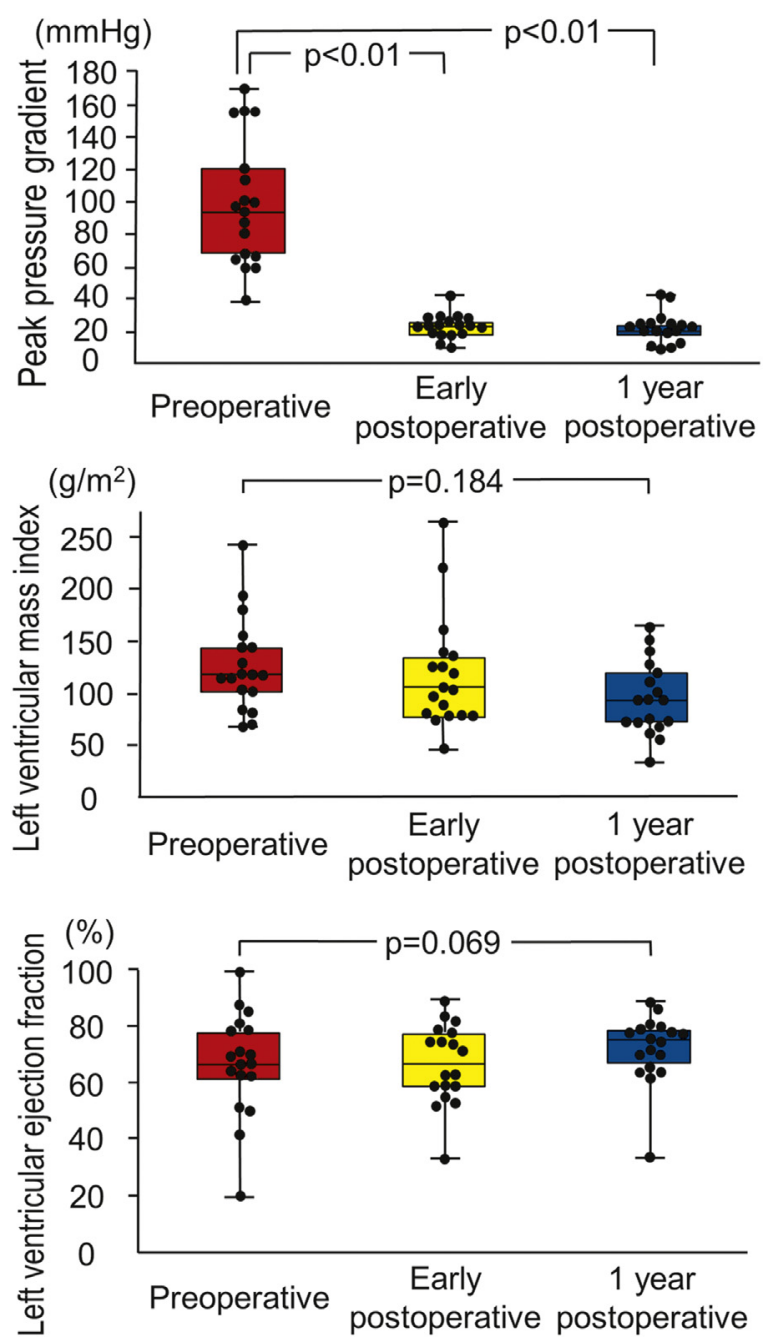

FIGURE 2. Echocardiographic data showed statistically significant decreases in the peak pressure gradient between preoperative and each set of follow-up measurements. No difference in left ventricular mass index $(P=.184)$ or left ventricular ejection fraction $(P=.069)$ were observed, between preoperative and 1-year postoperative measurements.

With this type of small valve, PPM should be considered. To prevent $\mathrm{PPM},{ }^{29,30}$ effective orifice area index at rest ideally should not be less than $0.85 \mathrm{~cm}^{2} / \mathrm{m}^{2}$. However, this goal must be evaluated in light of the anticipated risks and benefits for a given patient. ${ }^{31}$ Severe PPM (effective orifice area index $\leq 0.60 \mathrm{~cm}^{2} / \mathrm{m}^{2}$ ) is an independent predictor of higher long-term mortality and congestive heart failure in patients who have small St Jude Medical aortic valve prostheses. ${ }^{30}$

Additionally, $\mathrm{Hu}$ and colleagues ${ }^{29}$ reported that moderate PPM $\left(-0.65<\right.$ effective orifice area index $\left.<0.85 \mathrm{~cm}^{2} / \mathrm{m}^{2}\right)$ after AVR with a 17-mm SJM Regent valve in a small aortic annulus is associated with increased mortality and adverse events in patients who have pre-existing LV dysfunction (LV ejection fraction $<50 \%$ ). In addition, Blais and colleagues $^{32}$ observed that PPM is a strong and independent predictor of short-term mortality among patients undergoing AVR. On the basis of the positive results of AAE reported by Castro and colleagues, ${ }^{12}$ they recommend avoiding PPM by performing AAE. Furthermore, their study revealed that an LV ejection fraction of $<40 \%$, and cardiopulmonary bypass time of $>120$ minutes, are significant predictors of short-term mortality. They advised that moderate PPM in relatively inactive, older patients with normal LV function might be acceptable. Minardi and colleagues ${ }^{33}$ concluded that in relatively aged patients with small aortic annuli, the SJM Regent 17-mm valves can be implanted because of their satisfactory hemodynamic profile both at rest and under stress conditions.

In the current cohort, 2 patients were estimated to have a PPM before their operations; their body surface area (effective orifice area index) levels were $1.54(0.846)$ and 1.79 $(0.724) \mathrm{cm}^{2} / \mathrm{m}^{2}$. Both patients had a preoperative ejection fraction of $>40 \%$, but they tolerated $>120$ minutes of cardiopulmonary bypass time. In this series, all patients had extremely calcified or severely fragile aortic annuli, making completion by AVR alone difficult. Adding AAE to avoid PPM merely compounds the risk in these elderly patients who have a small body surface area. The moderate PPM incurred by the use of surgical AVR with a 17-mm mechanical valve to avoid AAE could be tolerable in such patients aged $>80$ years.

Amarelli and colleagues ${ }^{34}$ and Casali and colleagues ${ }^{35}$ reported significant $\mathrm{LV}$ mass index regression. By contrast, we did not find significant regression of LV mass index. Ejection fraction improvements were not observed in those studies, consistent with the current results. For their cohorts, ${ }^{34,35}$ the mean ( \pm standard deviation) for body surface area, age, and observed timing after operation were, respectively, $1.59( \pm 0.13) \mathrm{m}^{2}, 63.4( \pm 17.0)$ years, $2.4( \pm 1.9)$ years, and $1.63( \pm 0.21) \mathrm{m}^{2}, 66.9 \pm 12.1$ years, and $4.1 \pm 1.8$ years, respectively. Considering that the body surface area of this patient cohort was smaller $\left(1.39 \pm 0.15 \mathrm{~cm}^{2} / \mathrm{m}^{2}\right)$, the age was considerably advanced $(83.3 \pm 2.7$ years), and the observed timing after operation was shorter. Therefore, the effect of AVR may be limited. This observation further emphasizes the potential of using surgical AVR with a 17 -mm SJM Regent valve in patients aged $>80$ years who have small aortic annuli. Further investigations are needed to address aging-associated issues.

\section{Limitations}

If the patients in this cohort had been younger, did not have severely calcified aortic annuli, and had higher body surface area, we would have considered other procedures. We did not deliberately avoid the use of AAE or aortic root replacement. We were unexpectedly or unintentionally forced to do this procedure in some cases, in consideration of a patient's circumstances. Consequently, we collected these few patients into a study cohort. However, given 
that the sample size is small, inferences based on this sample may be biased.

\section{CONCLUSIONS}

We believe that the 17-mm SJM Regent valve should provide a safe surgical option for patients aged $>80$ years who have aortic annuli of $<19 \mathrm{~mm}$. No early perioperative mortality occurred. Patients' New York Heart Association functional class significantly improved, and most patients were recategorized as class I. Echocardiography showed a significant decrease in peak pressure gradient. The use of mechanical valves in patients aged $>80$ years is considered acceptable when implantation is followed by strict clinical monitoring to prevent thromboembolism and anticoagulation-therapy-induced complications.

\section{Conflict of Interest Statement}

Authors have nothing to disclose with regard to commercial support.

\section{References}

1. Emery RW, Krogh CC, Arom KV, Emery AM, Benyo-Albrecht K, Joyce LD, et al. The St. Jude Medical cardiac valve prosthesis: a 25-year experience with single valve replacement. Ann Thorac Surg. 2005;79:776-82.

2. Okamura H, Yamaguchi A, Nagano H, Itoh S, Morita H, Naito K, et al. Mid-term outcomes after aortic valve replacement with the 17-mm St. Jude Medical Regent valve. Circ J. 2012;76:365-71.

3. Okamura H, Yamaguchi A, Tanaka M, Naito K, Kimura N, Kimura C, et al. The 17-mm St. Jude Medical Regent valve is a valid option for patients with a small aortic annulus. Ann Thorac Surg. 2009;87:90-4.

4. Takaseya T, Kawara T, Tokunaga S, Kohno M, Oishi Y, Morita S. Aortic valve replacement with 17-mm St. Jude Medical prostheses for a small aortic root in elderly patients. Ann Thorac Surg. 2007;83:2050-3.

5. Nakamura Y, Nakano K, Tagusari O, Kataoka G, Seike Y, Domoto S, et al. An alternative option for elderly patients with a small aortic annulus: the $16 \mathrm{~mm}$ ATS valve. J Heart Valve Dis. 2009;18:691-7.

6. Peterson MD, Borger MA, Feindel CM, David TE. Aortic annular enlargement during aortic valve replacement: improving results with time. Ann Thorac Surg. 2007;83:2044-9.

7. Devereux RB, Reichek N. Echocardiographic determination of left ventricular mass in man. Anatomic validation of the method. Circulation. 1977;55:613-8.

8. Akins CW, Miller DC, Turina MI, Kouchoukos NT, Blackstone EH, Grunkemeier GL, et al. Guidelines for reporting mortality and morbidity after cardiac valve interventions. J Thorac Cardiovasc Surg. 2008;135:732-8.

9. Chiappini B, Camurri N, Loforte A, Di Marco L, Di Bartolomeo R, Marinelli G. Outcome after aortic valve replacement in octogenarians. Ann Thorac Surg. 2004;78:85-9.

10. George I, Yerebakan H, Kalesan B, Nazif T, Kodali S, Smith CR, et al. Age alone should not preclude surgery: contemporary outcomes after aortic valve replacement in nonagenarians. J Thorac Cardiovasc Surg. 2014;148:1360-9.

11. Coutinho GF, Correia PM, Paupério G, de Oliveira F, Antunes MJ. Aortic root enlargement does not increase the surgical risk and short-term patient outcome? Eur J Cardiothorac Surg. 2011:40:441-7.

12. Castro LJ, Arcidi JM Jr, Fisher AL, Gaudiani VA. Routine enlargement of the small aortic root: a preventive strategy to minimize mismatch. Ann Thorac Surg. 2002;74:31-6.

13. Kulik A, Al-Saigh M, Chan V, Masters RG, Bédard P, Lam BK, et al. Enlargement of the small aortic root during aortic valve replacement: Is there a benefit? Ann Thorac Surg. 2008;85:94-100.

14. Dhareshwar J, Sundt TM III, Dearani JA, Schaff HV, Cook DJ, Orszulak TA. Aortic root enlargement: What are the operative risks? J Thorac Cardiovasc Surg. 2007;134:916-24.

15. Mazzola A, Di Mauro M, Pellone F, Faragalli F, Villani C, Di Eusanio M, et al. Freestyle aortic root bioprosthesis is a suitable alternative for aortic root replacement in elderly patients: a propensity score study. Ann Thorac Surg. 2012;94:1185-90.
16. Ali A, Halstead JC, Cafferty F, Sharples L, Rose F, Coulden R, et al. Are stentless valves superior to modern stented valves? A prospective randomized trial. Circulation. 2006;114:I535-40.

17. Kobayashi J. Stentless aortic valve replacement: an update. Vasc Health Risk Manag. 2011;7:345-51.

18. Mack MJ, Leon MB, Smith CR, Miller DC, Moses JW, Tuzcu EM, et al. 5-year outcomes of transcatheter aortic valve replacement or surgical aortic valve replacement for high surgical risk patients with aortic stenosis (PARTNER 1): a randomised controlled trial. Lancet. 2015;385:2477-84.

19. Pibarot P, Weissman NJ, Stewart WJ, Hahn RT, Lindman BR, McAndrew T, et al. Incidence and sequelae of prosthesis-patient mismatch in transcatheter versus surgical valve replacement in high-risk patients with severe aortic stenosis: a PARTNER trial cohort — an analysis. J Am Coll Cardiol. 2014;64:1323-34.

20. Rodés-Cabau J, Pibarot P, Suri RM, Kodali S, Thourani VH, Szeto WY, et al Impact of aortic annulus size on valve hemodynamics and clinical outcomes after transcatheter and surgical aortic valve replacement: insights from the PARTNER Trial. Circ Cardiovasc Interv. 2014;7:701-11.

21. Handa N, Miyata H, Motomura N, Nishina T, Takamoto S. Procedure- and age-specific risk stratification of single aortic valve replacement in elderly patients based on Japan Adult Cardiovascular Surgery Database. Circ J. 2012;76: 356-64.

22. Nikolaidis N, Pousios D, Haw MP, Kaarne M, Barlow CW, Livesey SA, et al Long-term outcomes in octogenarians following aortic valve replacement. J Card Surg. 2011;26:466-71.

23. de Vincentiis C, Kunkl AB, Trimarchi S, Gagliardotto P, Frigiola A, Menicanti L, et al. Aortic valve replacement in octogenarians: Is biologic valve the unique solution? Ann Thorac Surg. 2008;85:1296-301

24. Nishimura RA, Otto CM, Bonow RO, Carabello BA, Erwin JP III, Guyton RA, et al. 2014 AHA/ACC Guideline for the management of patients with valvular heart disease: a report of the American College of Cardiology/American Heart Association Task Force on Practice Guidelines. Circulation. 2014;129:e521-643.

25. Barreto-Filho JA, Wang Y, Dodson JA, Desai MM, Sugeng L, Geirsson A, et al Trends in aortic valve replacement for elderly patients in the United States, 19992011. JAMA. 2013:310:2078-85.

26. Ashikhmina EA, Schaff HV, Dearani JA, Sundt TM III, Suri RM, Park SJ, et al. Aortic valve replacement in the elderly: determinants of late outcome. Circulation. 2011;124:1070-8.

27. Accola KD, Scott ML, Palmer GJ, Thompson PA, Sand ME, Suarez-Cavalier JE et al. Surgical management of aortic valve disease in the elderly: a retrospective comparative study of valve choice using propensity score analysis. J Heart Valve Dis. 2008; 17:355-64.

28. Vicchio M, Della Corte A, De Santo LS, De Feo M, Caianiello G, Scardone M et al. Tissue versus mechanical prostheses: quality of life in octogenarians. Ann Thorac Surg. 2008;85:1290-5.

29. Hu J, Qian H, Li YJ, Gu J, Zhao JJ, Zhang EY. Seventeen-millimeter St. Jude Medical Regent valve in patients with small aortic annulus: Does moderate prosthesis-patient mismatch matter? J Cardiothorac Surg. 2014;9:17.

30. Mohty D, Malouf JF, Girard SE, Schaff HV, Grill DE, Enriquez-Sarano ME, et al. Impact of prosthesis-patient mismatch on long-term survival in patients with small St Jude Medical mechanical prostheses in the aortic position. Circulation. 2006;113:420-6.

31. Pibarot P, Dumesnil JG. Hemodynamic and clinical impact of prosthesis-patien mismatch in the aortic valve position and its prevention. J Am Coll Cardiol. 2000; 36:1131-41.

32. Blais C, Dumesnil JG, Baillot R, Simard S, Doyle D, Pibarot P. Impact of valve prosthesis-patient mismatch on short-term mortality after aortic valve replacement. Circulation. 2003;108:983-8.

33. Minardi G, Manzara C, Creazzo V, Maselli D, Casali G, Pulignano G, et al. Evaluation of $17-\mathrm{mm}$ St. Jude Medical Regent prosthetic aortic heart valves by rest and dobutamine stress echocardiography. J Cardiothorac Surg. 2006;1:27.

34. Amarelli C, Della Corte A, Romano G, Iasevoli G, Dialetto G, De Santo LS, et al. Left ventricular mass regression after aortic valve replacement with $17-\mathrm{mm} \mathrm{St}$ Jude Medical mechanical prostheses in isolated aortic stenosis. J Thorac Cardiovasc Surg. 2005; 129:512-7.

35. Casali G, Luzi G, Vicchio M, della Monica PL, Minardi G, Musumeci F. Echocardiographic follow-up after implanting 17-mm Regent mechanical prostheses. Asian Cardiovasc Thorac Ann. 2008;16:208-11.

Key Words: aortic valve replacement, prosthesis, quality of life 